\title{
Iontophoretic delivery of nitric oxide donor improves local skin flap viability
}

\author{
John A. Russell, MS; ${ }^{1}$ Nadine P. Connor, PhD; ${ }^{1-2 *}$ Gregory K. Hartig, MD $^{1,3}$ \\ ${ }^{1}$ Department of Surgery, Division of Otolaryngology-Head and Neck Surgery, University of Wisconsin, Madison, WI; \\ ${ }^{2}$ Department of Communicative Disorders, University of Wisconsin, Madison, WI; ${ }^{3}$ William S. Middleton Memorial \\ Veterans Hospital, Madison, WI
}

\begin{abstract}
The dimensions of local flaps are often limited by the vascular supply to the distal aspect of the flap. Distal flap necrosis occurs if the vascular supply is inadequate. The purpose of this study was to investigate the use of iontophoretic delivery of nitric oxide (NO) donors to a local skin flap model to improve the survival area of the flap. Thirty-two male Sprague-Dawley rats (300 g) were divided into seven experimental groups to determine the effect of iontophoretic delivery of NO on surface perfusion and flap survival area. A caudally based $3 \times 11 \mathrm{~cm}$ dorsal skin flap was used to measure the effect of iontophoretic delivery of NO donors to a local skin flap to improve survival area of the flap. Iontophoretic delivery of the NO donors sodium nitroprusside (SNP) and diethylenetriamine NONOate (DETA-NO) resulted in a significant increase in survival area and surface perfusion when compared with sham controls. Iontophoretic delivery of saline was associated with a $13 \%$ improvement in flap survival when compared with nontreated controls. Iontophoretic delivery and subcutaneous injection of NO donors (SNP and DETA-NO) increased skin flap viability by demonstrating improved flap survival areas. The results of this study suggest that NO may serve as a postoperative treatment of skin flaps to encourage skin flap survival and prevent distal necrosis.
\end{abstract}

Key words: iontophoretic, necrosis, nitric oxide, NO, NO donor, rehabilitation, skin flaps, tissue, vascular supply, wound healing.

\section{INTRODUCTION}

Local skin flaps are commonly used in the repair of small-volume wounds. These local flaps generally have random pattern vascularity and are limited in their dimensions by the perfusion pressure within the supplying subdermal and dermal vascular plexus. The distal aspect of a local random pattern flap has the greatest risk of ischemic necrosis because of the limitations in vascular perfusion. Improvements in flap viability might be seen with manipulations that improve blood supply (i.e., use of vasodilators), decrease tissue damage caused by ischemia (i.e., use of free radical scavengers), or speed neovascularization (i.e., use of growth factors). Numerous studies have focused on intrinsic and extrinsic manipulations of local flaps to alter these processes [1-4]. External manipulations, such as preclamping or preconditioning, have been shown to improve flap viability; however, the mechanisms associated with these improvements are not well understood. The

Abbreviations: DETA-NO = diethylenetriamine NONOate, INJ = injection (delivery), $\mathrm{NO}=$ nitric oxide, $\mathrm{PBS}=$ phosphate-buffered saline, SNP = sodium nitroprusside, TID = transdermal iontophoretic delivery, VEGF = vascular endothelial growth factor.

* Address all correspondence to Nadine P. Connor, PhD; University of Wisconsin Clinical Science Center, Room K4/711, 600 Highland Avenue, Madison, WI 53792-7375; 608-2658711; fax: 608-263-7652. Email: connor@surgery.wisc.edu DOI:10.1682/JRRD.2008.10.0144 
preclamping method is based on the principle of ischemic preconditioning, which is defined as a brief period of ischemia followed by tissue reperfusion, which is thought to thereby improve ischemic tolerance for a longer period of ischemia [5]. Mounsey et al. were the first to examine the positive effects of preclamping [6], and this technique was then followed by other investigations [7-8]. A potential mechanism by which preconditioning improves flap survival may involve improved availability of nitric oxide (NO) within the flap tissue after the preconditioning period [9-10].

The beneficial effect of NO on tissue flap health has been demonstrated in a number of local flap studies. Supplementation of L-arginine as a substrate of NO has also been shown to significantly reduce necrosis in random pattern flaps [11] and porcine myocutaneous flaps [12]. Further, the use of NO inhibitors significantly increased flap necrosis in the random pattern flaps [11]. However, the clinical utility of NO donors has been limited by the absence of a method to effectively and safely deliver these agents to at-risk local flaps in humans. For example, simple topical application has limited absorption and availability, local injection may be traumatic to flap vasculature, and systemic administration is hampered by dilution and systemic side effects. As such, new methods of promoting increased NO within at-risk tissue should be explored.

A potential method of delivering $\mathrm{NO}$ to at-risk tissues is iontophoresis. Iontophoresis involves the use of alternating or direct electrical currents to drive the delivery of charged agents through tissues in order to improve delivery of these agents relative to levels delivered via simple diffusion.

Iontophoresis has been used clinically for improved delivery of local anesthetics and steroid treatments [1314]. However, it has rarely been used or studied in relation to the treatment of skin flaps [15]. This relative scarcity of investigations is surprising because evidence exists that electrical stimulation can itself affect and improve tissue repair [16-18]. Further, it has been shown that pulsed electrical stimulation can improve the survival of porcine skin flaps [19].

Therefore, iontophoresis was chosen for this study based on three major advantages over passive diffusion: (1) control of penetration can be linked to drug flux by the magnitude of the electrical current; (2) lag times are reduced or removed, making drug action more rapid; and (3) time of administration can be controlled by removal of the iontophoresis patch, which cannot be easily accomplished by topical formulations. This study investi- gated the use of iontophoretic delivery of NO donors to a local skin flap to improve survival area of the flap. We hypothesized that iontophoretic delivery of a NO donor would increase skin flap survival when compared with a nontreated control group.

\section{METHODS}

Thirty-two male Sprague-Dawley rats (average weight $=318 \mathrm{~g}$ ) were used for this study. In two experiments, animals were anesthetized with an intraperitoneal injection of a mixture of ketamine $(90 \mathrm{mg} / \mathrm{kg}$ ) and 1 percent xylazine $(9 \mathrm{mg} / \mathrm{kg})$. After shaving and depilating the back, a caudally based $3 \times 11 \mathrm{~cm}$ dorsal skin flap was elevated with the panniculus carnosus on all 32 rats [20]. All flaps were sutured into place with 4-0 silk and survived for 7 days.

Sodium nitroprusside (SNP) and diethylenetriamine NONOate (DETA-NO) served as NO donor molecules. The use of these molecules allowed investigation of NO donors with a rapid rate of NO release (SNP) versus a slower rate (DETA-NO). Although each pathway leading to NO formation differs among classes, all NO donors produce NO-related activity when applied and are thus well suited to mimic endogenous NO response [21].

The 32 rats were divided into 8 groups, and treatments were delivered either via injection (INJ) or transdermal iontophoretic delivery (TID). Groups and specific treatments are shown in the Table. The treatment groups in this study were-

1. Sham control, where flaps were created, but no treatment was delivered.

Table.

Groups ( $n=4$ for each) and treatments used in preliminary study of tissue flap survival as a function of nitric oxide treatment.

\begin{tabular}{ll}
\hline \multicolumn{1}{c}{ Group } & \multicolumn{1}{c}{ Treatment } \\
Control & No treatment \\
Saline INJ & $0.2 \mathrm{~mL}$ PBS injection treatment \\
Saline TID & $1 \mathrm{~mL}$ PBS TID treatment \\
SNP TID & $1 \mathrm{~mL}$ solution of $1.25 \mathrm{mg}$ SNP with PBS \\
SNP TID & $1 \mathrm{~mL}$ solution of $12.5 \mathrm{mg}$ SNP with PBS \\
DETA-NO TID & $1 \mathrm{~mL}$ solution of $2 \mathrm{mM}$ DETA-NO and PBS \\
SNP INJ & $0.2 \mathrm{~mL}$ INJ of 1.25 mg SNP with PBS \\
DETA-NO INJ & $0.2 \mathrm{~mL}$ INJ of DETA-NO mixed to $2 \mathrm{mM}$ \\
& solution in PBS \\
DETA-NO = diethylenetriamine NONOate, INJ = injection, PBS = phosphate- \\
buffered saline, SNP = sodium nitroprusside, TID = transdermal iontophoretic \\
delivery.
\end{tabular}


2. Saline TID to examine the effects of electrical stimulation of the skin; $1 \mathrm{~mL}$ phosphate-buffered saline (PBS) without NO.

3. Saline INJ; $0.2 \mathrm{~mL}$ PBS as a control for the INJ condition.

4. SNP TID; $1 \mathrm{~mL}$ solution of $1.25 \mathrm{mg}$ SNP with PBS.

5. SNP TID; $1 \mathrm{~mL}$ solution of $12.5 \mathrm{mg}$ SNP with PBS.

6. SNP INJ; $0.2 \mathrm{~mL}$ INJ of $1.25 \mathrm{mg}$ SNP with PBS.

7. DETA-NO TID; $1 \mathrm{~mL}$ solution of $2 \mathrm{mM}$ DETA-NO and PBS.

8. DETA-NO INJ; $0.2 \mathrm{~mL}$ INJ of DETA-NO mixed to $2 \mathrm{mM}$ solution in PBS.

Iontophoretic delivery was provided by a commercially available device (Iomed, Phoresor II, PM850; IOMED; Salt Lake City, Utah) using a small electrode with an area of $7.5 \mathrm{~cm}^{2}$ (Iogel, IOMED) and a current of $0.5 \mathrm{~mA} / \mathrm{cm}^{2}$ for 20 minutes. This dosage was chosen based on the maximum allowable setting without inducing burn or irritation. INJs and placement of the small electrode were made between the 5 and $6 \mathrm{~cm}$ mark from the caudal end of the flap. All INJ and TID treatments were given for the first 5 days of the 7-day posttreatment period. At 7 days after flap elevation, all flaps were photographed and planimetry data were analyzed by Simple PCI (Compix; Sewickley, Pennsylvania). In addition, laser Doppler imaging was performed on all flaps (PIM II scanning system, LDPIwin software version 2.0.9, Lisca Development; Linköping, Sweden). A one-way analysis of variance was used to test for differences between treatments in percentage of flap survival and surface perfusion of live tissue using an $\alpha$-level of 0.05 to determine statistical significance.

\section{RESULTS}

Figure 1 is a representative photograph demonstrating the increased tissue survival following NO donor INJ. Figure 2 summarizes the ability of NO donor INJ to augment survival and surface perfusion in rat skin flaps. As shown in Figure 2(a), INJs of both $1.25 \mathrm{mg}$ of SNP and DETA-NO (2 mM) significantly increased survival area by 40 and 33 percent, respectively, when compared with both saline INJ and sham controls ( $p=0.006$ and 0.02 , respectively). However, neither of the NO donors delivered via INJ had a significant effect on surface perfusion, as shown in Figure 2(b).

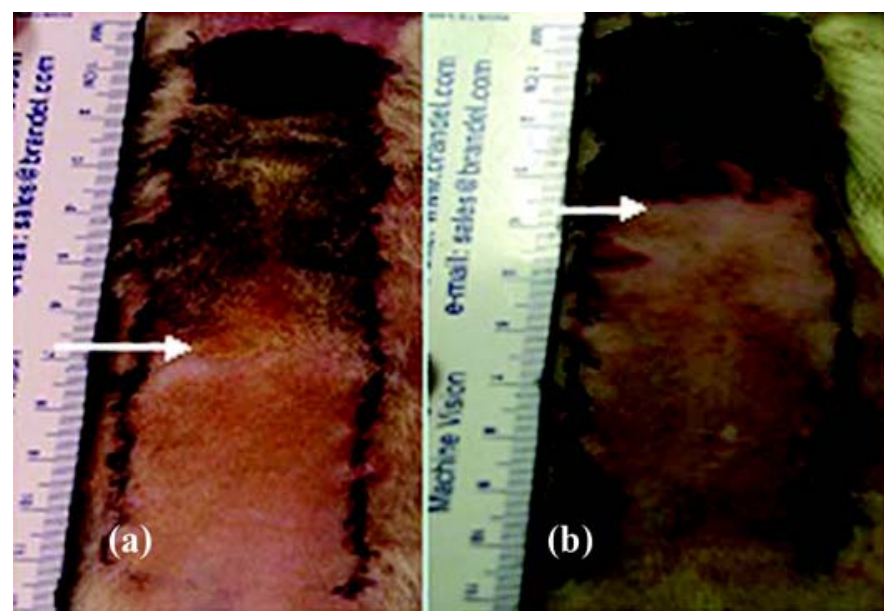

Figure 1.

Representative photograph of increased tissue survival noted following injection of nitric oxide donor DETA-NO. Arrows designate line of necrosis. (a) Control flap. (b) DETA-NO treated flap. DETA-NO = diethylenetriamine NONOate.

Figure 3 illustrates the effect of TID of SNP and DETA-NO on rat skin survival. A $2 \mathrm{mM}$ concentration DETA-NO TID resulted in a significant increase in survival area and surface perfusion when compared with sham controls $(p=0.01)$. In contrast to the INJ groups, $1.25 \mathrm{mg}$ of SNP with TID did not result in a significant increase in flap survival area when compared with sham controls. However, a higher dose of SNP (12.5 mg) TID approached a significant increase in flap survival $(p=0.06)$, and a significant increase in surface perfusion of flaps was seen with the higher dose when compared with SNP $1.25 \mathrm{mg}$ TID, sham control, and TID saline groups ( $p=0.02,0.002$, and 0.03, respectively, as shown in Figure 3(b)).

Confirming the utility of electrical stimulation alone, the TID saline group had a 13 percent improvement in flap survival when compared with nontreated controls. More importantly, DETA-NO delivered via TID more than doubled the improvements in survival area seen with electrical stimulation alone (TID saline group).

\section{DISCUSSION}

The purpose of this study was to assess whether administration of an NO donor through transdermal delivery would augment local skin flap survival. We observed that iontophoretic delivery and subcutaneous 
(a)

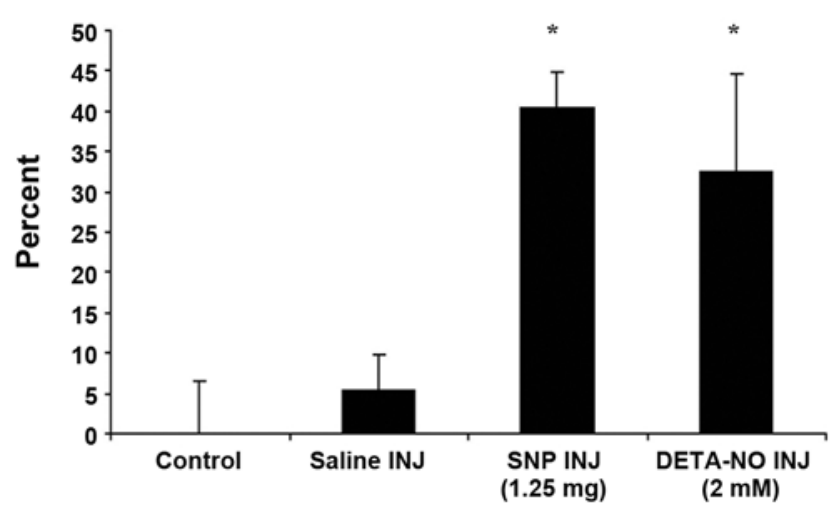

(b)

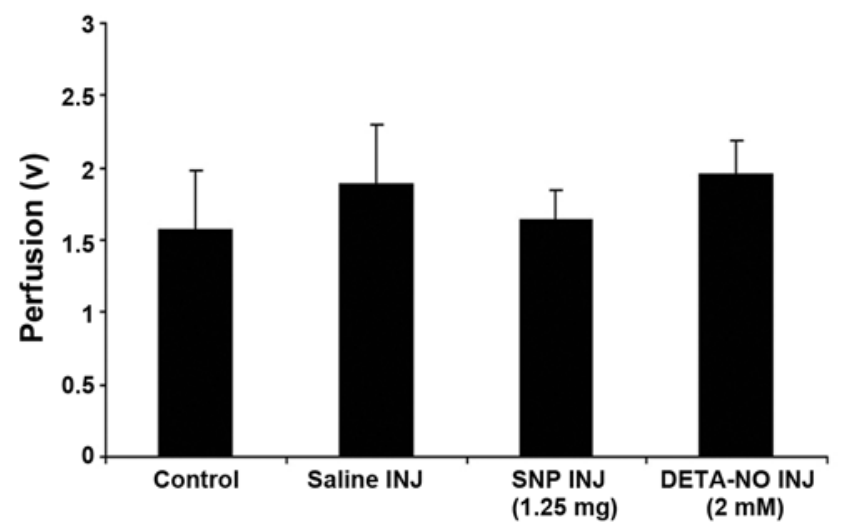

Figure 2.

(a) Average percentage increase in survival via injection (INJ) treatment with and without nitric oxide (NO) donors. (b) Flap perfusion of the different NO treatments and control. $n=4$ per group. Values are mean \pm standard deviation. ${ }^{*} p<0.05$ vs sham control and vs INJ control. DETA$\mathrm{NO}=$ diethylenetriamine NONOate, SNP = sodium nitroprusside.

(a)

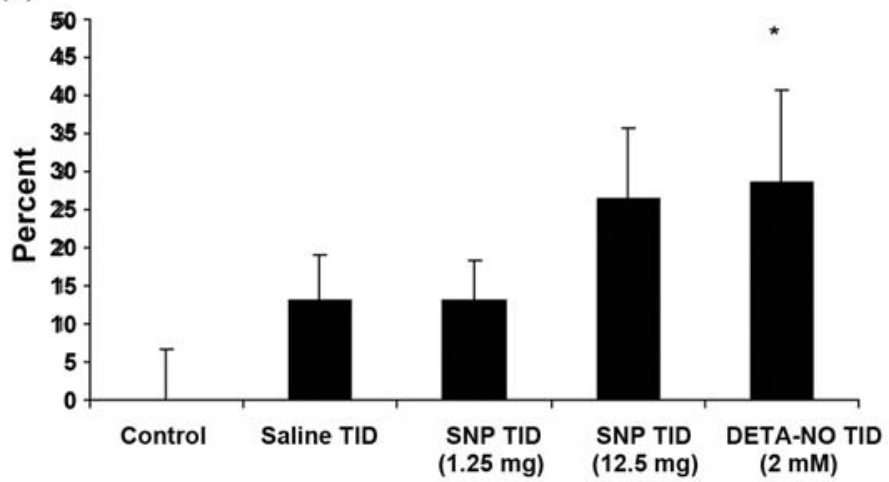

(b)

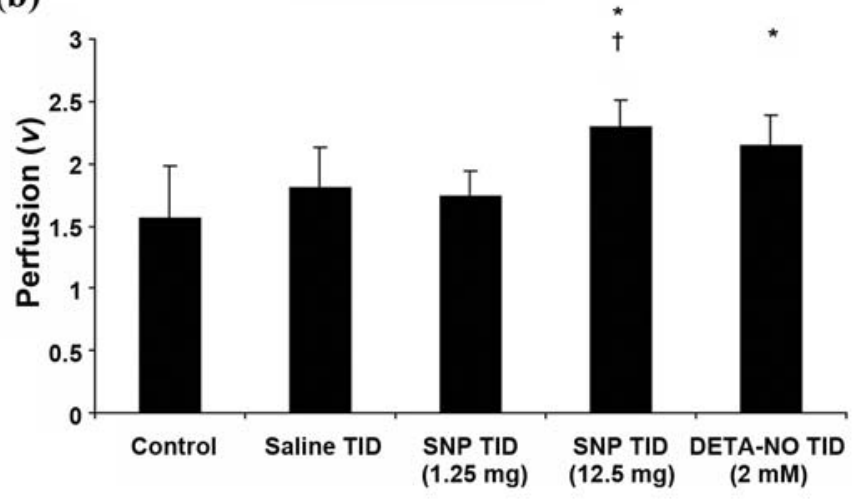

Figure 3.

(a) Average percentage increase in survival area via transdermal iontophoretic delivery (TID) treatment with and without nitric oxide (NO) donors. (b) Flap perfusion of the different NO treatments via TID treatment and control. $n=4$ per group. Values are mean \pm standard deviation. ${ }^{*} p<0.05$ vs sham control, ${ }^{\dagger} p<0.05$ vs Saline TID, Control, and SNP $1.25 \mathrm{mg}$ TID. DETA-NO = diethylenetriamine NONOate, SNP = sodium nitroprusside.

injection of NO donors (SNP and DETA-NO) increased skin flap viability by demonstrating improved flap survival areas. These findings allowed us to accept our hypothesis that iontophoretic delivery of NO donor may increase skin flap survival.

This study demonstrated the effectiveness of TID and INJ of NO donors in improving local flap surface perfusion and survival. In addition, although not a statistically significant increase, a 13 percent increase was found in survival area with electrical stimulation alone (TID saline), suggesting that electrical stimulation may promote skin flap survival. Although injection of NO donors proved beneficial, an injection mode of administration might not be clinically useful because of concerns that the injections themselves could produce trauma to the delicate subdermal and dermal vascular plexus of local flaps. The use of TID would eliminate this potential hazard.

Our results are consistent with prior studies that suggest that NO positively affects the wound healing process at several levels. NO is a mediator of angiogenesis by 
enhancing endothelial cell proliferation, perhaps in part by increasing the expression of vascular endothelial growth factor (VEGF) or fibroblast growth factor [22-24]. NO also enhances endothelial migration [25-26]. Finally, the hemodynamic effect of NO as a vasodilator may play a role in its angiogenic effects [27]. Recently, Khan et al. tested the effect of VEGF165 treatment on rat dorsal skin flap viability and discovered that the gains in skin flap viability seen with VEGF165 were reversed with the addition of the nonspecific NO inhibitor [3]. Therefore, they concluded that local subcutaneous injection of VEGF165 in skin flaps is effective in augmentation of skin flap viability by an increase in NO production and an associated increase in blood flow [3]. In summary, these studies suggest that NO improves blood flow before and during the neovascularization process and that these mechanisms are underlying the improvements in flap survival area observed in the current study.

\section{CONCLUSIONS}

The results of this study extend previous concepts regarding the role of NO and suggest that NO may also serve as a postoperative treatment of skin flaps to encourage skin flap survival and prevent distal necrosis. The present study successfully demonstrated the use of NO donors and electrical stimulation as a potential therapeutic treatment for the prevention of skin flap necrosis.

\section{ACKNOWLEDGMENTS}

\section{Author Contributions:}

Acquisition of data: J. A. Russell.

Analysis and interpretation of data: J. A. Russell, N. P. Connor.

Drafting of manuscript: J. A. Russell, N. P. Connor.

Revision of manuscript for important intellectual content: G. K. Hartig. Financial Disclosures: The authors have declared that no competing interests exist.

Funding/Support: This material was based on work supported by the Department of Veterans Affairs, Rehabilitation Research and Development Service.

Additional Contributions: The authors gratefully acknowledge the assistance of biostatistician Alejandro Munoz-del-Rio and medical editor Kelsey Anderson in the completion of this work.

Institutional Review: This study was performed in accordance with the Public Health Service Policy on Humane Care and Use of Laboratory Animals, the National Institutes of Health Guide for the Care and Use of Laboratory Animals, and the Animal Welfare Act (7 U.S.C. et seq.): the animal use protocol was approved by the Institutional Ani- mal Care and Use Committees (IACUC) of University of Wisconsin and William S. Middleton Memorial Veterans Hospital.

\section{REFERENCES}

1. Clugston PA, Perry LC, Fisher J, Maxwell GP. A rat transverse rectus abdominis musculocutaneous flap model: Effects of pharmacological manipulation. Ann Plast Surg. 1995; 34(2):154-61. [PMID: 7741433] DOI:10.1097/00000637-199502000-00007

2. Giunta RE, Holzbach T, Taskov C, Holm PS, Konerding MA, Schams D, Biemer E, Gänsbacher B. AdVEGF165 gene transfer increases survival in overdimensioned skin flaps. J Gene Med. 2005;7(3):297-306. [PMID: 15515117] DOI:10.1002/jgm.675

3. Khan A, Ashrafpour H, Huang N, Neligan PC, Kontos C, Zhong A, Forrest CR, Pang CY. Acute local subcutaneous VEGF165 injection for augmentation of skin flap viability: Efficacy and mechanism. Am J Physiol Regul Integr Comp Physiol. 2004;287(5):R1219-29. [PMID: 15217788] DOI:10.1152/ajpregu.00143.2004

4. Lohman R, Yowell R, Barton S, Araneo B, Siemionow M. Dehydroepiandrosterone protects muscle flap microcirculatory hemodynamics from ischemia/reperfusion injury: An experimental in vivo study. J Trauma. 1997;42(1):74-80.

[PMID: 9003261]

DOI:10.1097/00005373-199701000-00013

5. Küntscher MV, Kastell T, Engel H, Gebhard MM, Heitmann C, Germann G. Late remote ischemic preconditioning in rat muscle and adipocutaneous flap models. Ann Plast Surg. 2003;51(1):84-90. [PMID: 12838130] DOI:10.1097/01.SAP.0000054186.10681.E2

6. Mounsey R, Pang CY, Forrest C. Preconditioning: A new technique for improved muscle flap survival. Otolaryngol Head Neck Surg. 1992;107(4):549-52. [PMID: 1437186$]$

7. Zahir K, Syed SA, Zink JR, Restifo RJ, Thomson JG. Ischemic preconditioning improves the survival of skin and myocutaneous flaps in a rat model. Plast Reconstr Surg. 1998;102(1):140-50. [PMID: 9655419] DOI:10.1097/00006534-199807000-00022

8. Wang WZ, Anderson G, Firrell JC, Tsai TM. Ischemic preconditioning versus intermittent reperfusion to improve blood flow to a vascular isolated skeletal muscle flap of rats. J Trauma. 1998;45(5):953-59. [PMID: 9820708] DOI:10.1097/00005373-199811000-00018

9. Wang WZ, Anderson GL, Guo SZ, Tsai TM, Miller FN. Initiation of microvascular protection by nitric oxide in late preconditioning. J Reconstr Microsurg. 2000;16(8):621-28. [PMID: 11127285] DOI:10.1055/s-2000-9380 
10. Küntscher MV, Kastell T, Altman J, Menke H, Gebhard MM, Germann G. Acute remote ischemic preconditioning II: The role of nitric oxide. Microsurgery. 2002;22(6):227-31.

[PMID: 12375287]

DOI:10.1002/micr.10042

11. Um SL, Suzuki S, Toyokuni S, Kim BM, Tanaka T, Hiai H, Nishimura Y. Involvement of nitric oxide in survival of random pattern skin flap. Plast Reconstr Surg. 1998;101(3): 785-92. [PMID: 9500397] DOI:10.1097/00006534-199803000-00030

12. Cordeiro PG, Santamaria E, Hu QY. Use of a nitric oxide precursor to protect pig myocutaneous flaps from ischemiareperfusion injury. Plast Reconstr Surg. 1998;102(6):2040-48. [PMID: 9811002] DOI:10.1097/00006534-199811000-00035

13. Meyer DR, Linberg JV, Vasquez RJ. Iontophoresis for eyelid anesthesia. Ophthalmic Surg. 1990;21(12):845-48. [PMID: 2096345]

14. Glass JM, Stephen RL, Jacobson SC. The quantity and distribution of radiolabeled dexamethasone delivered to tissue by iontophoresis. Int J Dermatol. 1980;19(9):519-25. [PMID: 7429701] DOI:10.1111/j.1365-4362.1980.tb00380.x

15. Asai S, Fukuta K, Torii S. Topical administration of prostaglandin E1 with iontophoresis for skin flap viability. Ann Plast Surg. 1997;38(5):514-17. [PMID: 9160134] DOI:10.1097/00000637-199705000-00012

16. Heppenstall RB. Constant direct-current treatment for established nonunion of the tibia. Clin Orthop Relat Res. 1983; 178:179-84. [PMID: 6603940]

17. Konikoff JJ. Electrical promotion of soft tissue repairs. Ann Biomed Eng. 1976;4(1):1-5. [PMID: 1084717] DOI:10.1007/BF02363553

18. Su CT, Im MJ, Hoopes JE. Tissue glucose and lactate following vascular occlusion in island skin flaps. Plast Reconstr Surg. 1982;70(2):202-5. [PMID: 7048369] DOI:10.1097/00006534-198208000-00014

19. Im MJ, Lee WP, Hoopes J. Effect of electrical stimulation on survival of skin flaps in pigs. Phys Ther. 1990;70(1):37-40. [PMID: 2294531]

20. McFarlane RM, DeYoung G, Henry RA. The design of a pedicle flap in the rat to study necrosis and prevention.
Plast Reconstr Surg. 1965;35:177-82. [PMID: 14264468]

DOI:10.1097/00006534-196502000-00007

21. Feelisch $\mathrm{M}$. The use of nitric oxide donors in pharmacological studies. Naunyn-Schmiedebergs Arch Pharmacol. 1998; 358(1):113-22. [PMID: 9721012]

DOI:10.1007/PL00005231

22. Papapetropoulos A, García-Cardeña G, Madri JA, Sessa WC. Nitric oxide production contributes to the angiogenic properties of vascular endothelial growth factor in human endothelial cells. J Clin Invest. 1997;100(12):3131-39.

[PMID: 9399960]

DOI:10.1172/JCI119868

23. Dulak J, Jozkowicz A. Nitric oxide in vascular endothelial growth factor synthesis and signaling. Circulation. 2001; 104(9):E48-49. [PMID: 11524413]

24. Ziche M, Morbidelli L, Choudhuri R, Zhang HT, Donnini S, Granger HJ, Bicknell R. Nitric oxide synthase lies downstream from vascular endothelial growth factor-induced but not basic fibroblast growth factor-induced angiogenesis. J Clin Invest. 1997;99(11):2625-34. [PMID: 9169492] DOI:10.1172/JCI119451

25. Ziche M, Parenti A, Ledda F, Dell'Era P, Granger HJ, Maggi CA, Presta M. Nitric oxide promotes proliferation and plasminogen activator production by coronary venular endothelium through endogenous bFGF. Circ Res. 1997; 80(6):845-52. [PMID: 9168787]

26. Murohara T, Asahara T, Silver M, Bauters C, Masuda H, Kalka C, Kearney M, Chen D, Symes JF, Fishman MC, Huang PL, Isner JM. Nitric oxide synthase modulates angiogenesis in response to tissue ischemia. J Clin Invest. 1998; 101(11):2567-78. [PMID: 9616228] DOI:10.1172/JCI1560

27. Hudlická O, Brown MD, Silgram H. Inhibition of capillary growth in chronically stimulated rat muscles by $\mathrm{N}(\mathrm{G})$ nitro-l-arginine, nitric oxide synthase inhibitor. Microvasc Res. 2000;59(1):45-51. [PMID: 10625570$]$ DOI:10.1006/mvre.1999.2193

Submitted for publication October 31, 2008. Accepted in revised form October 5, 2009. 